\title{
Prevention and Management of Surgical Site Infection after Cardiac Surgery: A Case Study
}

\author{
Shinta Novelia ${ }^{1 *}$ and Khomapak Maneewat ${ }^{2}$ \\ 1 Faculty of Health Sciences, Universitas Nasional, Indonesia; \\ ${ }^{2}$ Faculty of Nursing, Prince of Songkla University Thailand; \\ *Correspondence: shinta.novelia@civitas.unas.ac.id \\ Type of the Paper (Article)
}

Received: July 27, 2020; Accepted: August 16, 2020; Published: September 3, 2020 https://doi.org/10.29253/achnr.2020.2133

\begin{abstract}
Surgical Site Infection (SSI) is the most common health care-associated infection. SSI causes functional disability and emotional stress to the patients and led to reduce quality of life. SSI leads to increased pain, anxiety, prolong hospital stay and even death. Preventing SSI in post cardiac surgery is a challenge for nurses and community since the wound care is presenting in the hospital and at home. This study aimed to analyze the implementation and prevention of SSI among patients post cardiac surgery. This case study was conducted in Male Surgical Ward and Surgical Intensive Care Unit (ICU) of the Songklanagarind Hospital Thailand in 2015. Intervention was developed based on Centre for Disease Control guideline of SSI (1999). The results found that the prevention of surgical site infections is not a result of isolated actions taken by one provider. Rather, it is the objective and desired outcome of an integrated team process. Nurses, patients, and caregiver need to have enough knowledge and awareness to prevent SSI.
\end{abstract}

Keywords: surgical site infection; prevention; management; post cardiac surgery

\section{Introduction}

Surgical site infection (SSI) is the second most common health care-associated infection and accounts for $14 \%$ to $16 \%$ of hospital-acquired infections (Health Care Associated Infections, 2013). The mortality rate of SSI has been found among patient with post cardiac surgery, and it ranges between 825\% (Hosseinrezaei, Rafiei, \& Amiri, 2012). Studies on the incidence of wound infection at the site of the surgical incision in cardiac surgery patients have reported a variety of results. The incidence of reoperation for deep incisional SSI in the UK was reported as $0.6 \%$, with a further $0.5 \%$ having a sterile sternal re-suture (Bridgewater, Kinsman, \& Walton, 2009).

SSI causes functional disability and emotional stress to the patients, instead of in some cases disabling condition led to reducing the quality of life (Ponce-de-Leon, 1991 as cited in Sickder 2010). In hospital, SSI causes increased health care cost regarding prolonging hospital stay and increased antibiotic consumption (Harington, 2014). In addition, it also leads to increased pain, anxiety, cause the prolonged recovery for patients, further risk of complications and in some cases are death (Harrington, 2014). Due to its associated with significant patient morbidity and mortality, SSI is the third most frequently reported health care associated infection (Blackham, 2013). The risk factor of SSI in in cardiac surgery included smoking, diabetes, obesity, old age, malnutrition, the preoperative assessment and preparation 
of the patient, the perioperative environment, surgical technique, history of diseases in the pulmonary system (COPD), and steroid use (Edmiston \& Spencer, 2014; Hosseinrezaei, 2012; Lobley, 2013; Mangram, 2012).

The Centers for Disease Control and Prevention guidelines for the prevention of SSIs emphasize the importance of proper patient preparation, aseptic practice, and attention to surgical technique; antimicrobial prophylaxis is also indicated in specific circumstances (Mangram, 1999). The pre-operative prevention strategies included protect the wound of incision that has been closed primarily with a sterile dressing for 24 to 48 hours postoperative, wash hand before and after changing the wound dressing, prevent any contact with the surgical site and educate the patient and family regarding proper incision care.

To prevent and manage SSI in post-cardiac surgery is a challenge in nursing because nurses can manage some factors. Hospital nurse and community nurse is the key to manage surgical site infection. A study revealed that the infection rate after discharge was higher than the inpatient rate (Reilly et al., 2019). Furthermore, another study found that there was an increased risk of post discharge SSI after some types of surgical procedures (Prospero et al., 2006). Nurses take a major role and responsibility in prevention of SSI but remain lack of adequate knowledge as a study conducted in Belgium which reflects the nurse's knowledge of SSI prevention was only 29\% (Labeau, 2010). A study conducted in Indonesia (Novelia et al., 2017) found that nurses had a low level of knowledge regarding SSI prevention. Updated knowledge about evidence-based recommendation is necessary to provide high-quality nursing care. Nurses play a leading role in initiatives that aim to minimize the risk of SSI, and thus to enhance patient safety. Therefore, this paper will implement the intervention to prevent and manage surgical site infection among patients undergoing cardiac surgery.

\section{Objectives}

a. To analyze the risk factors of SSI among patient undergoing cardiac surgery

b. To describe SSI among patients undergoing cardiac surgery

c. To evaluate the effectiveness of evidence-based nursing intervention to prevent SSI among patients undergoing cardiac surgery.

\section{Methodology of the Study}

\section{Subject criteria}

Patients undergoing cardiac surgery with their family who were willing to participate in the phenomenon study.

\section{Informed consent}

This study was a part of the Advance Nursing Practicum for Adult clients. This study was conducted in the Male Surgical Ward and Surgical ICU of the Songklanagarind Hospital Thailand in 2015. All patients were posting cardiac surgery. Patients and their caregivers were explained about the purpose, activity and plan. They were confirmed that the data were recorded with confidentiality. In addition, permission from patients and caregivers were obtained before the procedure.

\section{Data Collection Tool}

Demographic data assessed such as age, gender, marital status, education level, history of surgery and disease, medical diagnosis, active problem list, operative note, and preoperative physical status. The tool of SSI was used to analyze the risk factors and intervention of SSI. The pre-operative data were collected from the computer and asked the nurses. The intraoperative data were collected by asked the surgeon. The post-operative data were collected from the computer, asked to the nurses, observed patients and the observed nurses when they were caring patients. Patients and caregiver were asked open-ended questionnaire to get in-depth information related to knowledge about SSI. Patient education intervention used the leaflet which contains information about definition, risk factors, when do the SSI develop, how will a patient know if they have SSI, signs and symptoms of SSI, need a report of that sign and symptoms, and how to prevent SSI. 


\section{Intervention}

The intervention was developed based on CDC guideline of SSI (1999). The post-operative prevention strategies included protecting wound with a sterile dressing for 24 to 48 hours postoperatively, washing hands and using sterile technique before and after wound dressing and any contact with the surgical site, and educate the patient and family regarding proper incision care, symptoms of SSI, and the need to report such symptoms. The intervention was delivered to patients who met the inclusion criteria. The interventions were provided individually by nurse, doctor, medical students, master student, and also collaboration with Lecturer. The interventions were delivered to prevent SSI. The signs and symptoms of SSI were recorded and evaluated during three days of clinical practice.

\section{4. $\quad$ Findings}

\section{Patient I}

Mr. A, 74 years old came with a chief complaint of chest pain 6 hours before admission in Pattalung Hospital on 17/04/2015. The 12 lead EKG showed T wave invert. The patient was treated with tab ASA 81, ISDN $5 \mathrm{mg}$, Enoxaparin $0.5 \mathrm{ml}$ and on the same day he was referred to PSU Hospital for CAG. After that he had CAG at PSU hospital and was diagnosed with Triple vessel disease (TVD) and plan to follow up schedule for the CABG operation on 11/5/15 and returned home with medication. On 21/4/15 he got chest pain suddenly which worsened even he took a rest, after that he came to PSU hospital on the same day. At PSU hospital, the patient had CABG operation at 23/4/15.

\section{Patient II}

Patient with chest pain suddenly to Naconsitamarat, scale 10 out of 10 , and he was referred to PSU hospital with the medical diagnosis was thoracic aortic dissection type A and take emergency surgery (ascending aortic replacement with Dacron graft) on admission date May 4 2015. EKG showed ST elevated. He had a history of smoking 10 pieces per day.

\section{Patient III}

The patient was referred from Phuket Hospital because he had sudden chest pain 15 minutes before he went to the hospital after that, he was diagnosed as aortic dissection type I and in echo, there was seen a ruptured sinus of valsava. Then he was referred in PSU hospital for aortic replacement in PSU during admission his vital signs were BP: 70/50, P: 80/min, RR:20/min and saturation 90\%. He had ascending aortic replacement with dacron graft surgery on April 23rd, 2015.

\section{Patient IV}

Patient readmitted in PSU hospital due to a had high fever and known case bicuspid AV with mild AS, pulmonary hypertension, ruptured sinus of valsava 25/3/15, post and cardiotomy syndrome. Last admission on April 8-23, 2015 due to gram-positive (S.aureus) septicemia source, wound dehiscence mediastinitis.

\section{Patient V}

Patient bed no. 12 (77 years old), six months before coming to PSU hospital, he got dyspnea and he also felt chest pain then he went to the Hospital in his province. He was diagnosed MI and got medication coagulation, and then he was referred to PSU Hospital. Past is History: COPD. He had CABG surgery in PSU Hospital on May 6 $6^{\text {th }}, 2015$.

The following table is the detail risk factors of SSI which were found among patients, and the interventions that were developed to reduce SSI: 
Table 1. Patient's characteristic.

\begin{tabular}{lccccc}
\hline Patient's Characteristic & $\begin{array}{c}\text { Patient } \\
\text { I }\end{array}$ & $\begin{array}{c}\text { Patient } \\
\text { II }\end{array}$ & $\begin{array}{c}\text { Patient } \\
\text { III }\end{array}$ & $\begin{array}{c}\text { Patient } \\
\text { IV }\end{array}$ & $\begin{array}{c}\text { Patient } \\
\text { V }\end{array}$ \\
\hline Age & 74 years & 61 years & 39 years & 58 years & 77 years \\
& old & old & old & old & old \\
Duration of surgery & 5 hours & 7 hours & 7 hours & 6 hours & 6 hours \\
Preoperative physical status & Normally & Normally & Normally & Normally & Normally \\
healthy & healthy & healthy & healthy & healthy \\
Diabetes & Yes & No & No & Yes & No \\
Malnutrition & Yes & Yes & Yes & Yes & Yes \\
Steroid use & No & No & No & No & No \\
Smoking & No & Yes & No & No & No \\
Obesity & No & No & Yes & No & No \\
Pre-operative nares colonization with & No & No & No & No & No \\
S. Aureus & & & & & \\
Perioperative transfusion & Yes & Yes & Yes & Yes & Yes \\
Prolong hospital stay & 3 days & 1 day & 2 days & 2 day & 2 days \\
\hline
\end{tabular}

Table 1 shows that the participants age ranged from 39 to 77 years old, the duration of surgery ranged from five to seven hours, all patients had a normally healthy preoperative physical status, three patients had no diabetes mellitus, all patients were malnourished, no patients used steroid, one patient was smoking, one patient was obese, no patient had pre-operative nares colonization with S. Aureus, all patients had perioperative transfusion and the hospital stay range between one to three days.

Table 2. Pre-operative issues.

\begin{tabular}{|c|c|c|c|c|c|}
\hline Intraoperative issue & $\begin{array}{c}\text { Patient } \\
\text { I }\end{array}$ & $\begin{array}{c}\text { Patient } \\
\text { II }\end{array}$ & $\begin{array}{c}\text { Patient } \\
\text { III }\end{array}$ & $\begin{array}{c}\text { Patient } \\
\text { IV }\end{array}$ & $\begin{array}{c}\text { Patient } \\
\text { V }\end{array}$ \\
\hline Pre-operative antiseptic showering & Yes & No & Yes & Yes & Yes \\
\hline Pre-operative hair removal & Yes & Yes & Yes & Yes & Yes \\
\hline $\begin{array}{l}\text { Pre-operative skin preparation in the } \\
\text { operating room }\end{array}$ & Yes & Yes & Yes & Yes & Yes \\
\hline Pre-operative hands/ forearm antiseptic & Yes & Yes & Yes & Yes & Yes \\
\hline $\begin{array}{l}\text { Management of infected or colonized } \\
\text { surgical personnel }\end{array}$ & Yes & Yes & Yes & Yes & Yes \\
\hline Antimicrobial prophylaxis & Yes & Yes & Yes & Yes & Yes \\
\hline
\end{tabular}

Table 2 shows that all patients had a complete procedure of preoperative issues included preoperative antiseptic showering, preoperative hair removal, preoperative skin preparation in the operating room, preoperative hands/ forearm antiseptic, management of infected or colonized surgical personnel and antimicrobial prophylaxis. 
Table 3. Intraoperative issues.

\begin{tabular}{|c|c|c|c|c|c|}
\hline Preoperative issue & $\begin{array}{c}\text { Patient } \\
\text { I }\end{array}$ & $\begin{array}{c}\text { Patient } \\
\text { II }\end{array}$ & $\begin{array}{c}\text { Patient } \\
\text { III }\end{array}$ & $\begin{array}{c}\text { Patient } \\
\text { IV }\end{array}$ & $\begin{array}{c}\text { Patient } \\
\mathrm{V} \\
\end{array}$ \\
\hline $\begin{array}{l}\text { Operating room environment } \\
\text { Ventilation } \\
\text { - Microbiologic sampling } \\
\text { - } \quad \text { Conventional sterilization of } \\
\quad \text { surgical instruments }\end{array}$ & Yes & Yes & Yes & Yes & Yes \\
\hline $\begin{array}{l}\text { Surgical attire and drapes } \\
\text { - Scrub suits } \\
\text { - Masks } \\
\text { - Surgical caps/hoods and shoe } \\
\text { - Sterile gloves } \\
\text { - Gowns and drapes }\end{array}$ & Yes & Yes & Yes & Yes & Yes \\
\hline $\begin{array}{l}\text { Asepsis and surgical technique } \\
\text { - Asepsis } \\
\text { - Surgical technique }\end{array}$ & Yes & Yes & Yes & Yes & Yes \\
\hline
\end{tabular}

Table 3 shows that all patients had a complete intra operative procedure including operating room environment ventilation, surgical attire and drapes, and asepsis and surgical technique.

Table 4. Post-operative issues.

\begin{tabular}{llcccc}
\hline Post-operative issue & Patient & Patient & Patient & Patient & $\begin{array}{c}\text { Patient } \\
\text { IV }\end{array}$ \\
& I & II & III & IV & V \\
\hline Incision care & Yes & Yes & Yes & Yes & Yes \\
Discharge planning & Yes & Yes & Yes & Yes & Yes \\
\hline
\end{tabular}

Table 4 shows that all patients had a complete post-operative procedure including incision care and discharge planning.

Table 5. Wound classification and assessment of SSI.

\begin{tabular}{|c|c|c|c|c|c|c|}
\hline No & Finding & $\begin{array}{c}\text { Patient } \\
\text { I }\end{array}$ & $\begin{array}{l}\text { Patient } \\
\text { II }\end{array}$ & $\begin{array}{l}\text { Patient } \\
\text { III }\end{array}$ & $\begin{array}{l}\text { Patient } \\
\text { IV }\end{array}$ & $\begin{array}{c}\text { Patient } \\
\text { V }\end{array}$ \\
\hline 1 & $\begin{array}{l}\text { Wound } \\
\text { classification }\end{array}$ & Class I & Class I & Class I & Class I & Class I \\
\hline 2 & $\begin{array}{l}\text { Signs and } \\
\text { symptoms of SSI } \\
\text { finding }\end{array}$ & - & - & - & $\begin{array}{l}\text { Deep incisional SSI } \\
\text { - wound dehisces of } \\
\text { deep incision, } \\
\text { fever }\left(>38^{\circ} \mathrm{C}\right) \text {, } \\
\text { localized pain, } \\
\text { heat around the } \\
\text { wound, finding of } \\
\text { S.Aureus in the } \\
\text { blood culture }\end{array}$ & $\begin{array}{l}\text { Superficial SSI: } \\
\text { - Purulent } \\
\text { drainage from } \\
\text { the superficial } \\
\text { incision on the } \\
\text { leg. }\end{array}$ \\
\hline
\end{tabular}

Table 5 shows that 2 patients had surgical site infection. Patient IV had deep incisional SSI which marked by wound dehisces of deep incision, fever ( $>380 \mathrm{C}$ ), localized pain, heat around the wound, finding of S.Aureus in the blood culture. In addition, patient $\mathrm{V}$ had superficial SSI which marked by purulent drainage from the superficial incision on the leg. 
Table 6. Post-operative prevention strategies.

\begin{tabular}{|c|c|c|c|c|c|c|}
\hline No & Activity & $\begin{array}{c}\text { Patient } \\
\text { I }\end{array}$ & $\begin{array}{c}\text { Patient } \\
\text { II }\end{array}$ & $\begin{array}{c}\text { Patient } \\
\text { III }\end{array}$ & $\begin{array}{c}\text { Patient } \\
\text { IV }\end{array}$ & $\begin{array}{c}\text { Patient } \\
\text { V }\end{array}$ \\
\hline 1 & $\begin{array}{l}\text { Protect with a sterile dressing for } 24 \text { to } \\
48 \text { hours postoperatively an incision that } \\
\text { has been closed primarily }\end{array}$ & Yes & Yes & Yes & Yes & Yes \\
\hline 2 & $\begin{array}{l}\text { Wash hands before and after dressing } \\
\text { changes and any contact with the surgical } \\
\text { site }\end{array}$ & Yes & Yes & Yes & Yes & Yes \\
\hline 3 & $\begin{array}{l}\text { When an incision dressing must be } \\
\text { changed, use sterile technique }\end{array}$ & Yes & Yes & Yes & Yes & Yes \\
\hline 4 & $\begin{array}{l}\text { Educate the patient and family regarding } \\
\text { proper incision care, symptoms of SSI, } \\
\text { and the need to report such symptoms. }\end{array}$ & Yes & Yes & Yes & Yes & Yes \\
\hline
\end{tabular}

Table 6 shows that all patients had a post-operative prevention strategies which including protect with a sterile dressing for 24 to 48 hours postoperatively an incision that has been closed primarily, wash hands before and after dressing changes and any contact with the surgical site, when an incision dressing must be changed, use sterile technique, educate the patient and family regarding proper incision care, symptoms of SSI, and the need to report such symptoms.

Table 7. Intervention to improve SSI (Gould, 2012).

\begin{tabular}{|c|c|c|c|}
\hline No & Intervention & Patient IV & Patient V \\
\hline 1 & Optimal fluid and electrolyte balance & Yes & Yes \\
\hline 2 & $\begin{array}{l}\text { Optimal nutritional status, with correction of } \\
\text { negative nitrogen balance }\end{array}$ & Yes & Yes \\
\hline 3 & Correction of a low haemoglobin level. & Yes & Yes \\
\hline 4 & $\begin{array}{l}\text { Control of any underlying metabolic disorder, } \\
\text { for example diabetes mellitus }\end{array}$ & No & Yes \\
\hline 5 & $\begin{array}{l}\text { Opportunity to learn and practice deep } \\
\text { breathing and leg exercises }\end{array}$ & Yes & Yes \\
\hline 6 & $\begin{array}{l}\text { Opportunity to discuss the operation, } \\
\text { anticipate what will happen in hospital. }\end{array}$ & Yes & Yes \\
\hline
\end{tabular}

Table 7 shows that 2 patients who had SSI received intervention to improve SSI which including optimal fluid and electrolyte balance, optimal nutritional status with correction of negative nitrogen balance, correction of a low haemoglobin level, control of any underlying metabolic disorder, for example diabetes mellitus, opportunity to learn and practice deep breathing and leg exercises, opportunity to discuss the operation, and anticipate what will happen in hospital.

\section{Discussion}

There were five male patients with post-cardiac surgery included in this study. The first patient was diagnosed with TVD and had CABG, second patient was diagnosed thoracic aortic dissection type A and had ascending aortic replacement with dacron graft, the third patient was diagnosed with pericardial effusion without cardiac tamponade and had ascending aortic replacement with dacron graft, the fourth patient was diagnosed with repair rupture sinus of valsava surgery with wound dehiscence mediastinis.

From five patients, there were different and similar risk factors that contribute to SSI. The similar risk factors included patient's characteristics (perioperative transfusion and duration of surgery), perioperative issues (pre-operative hair removal, preoperative skin preparation in the operating room, pre-operative hands/forearm antiseptic, management of infected or colonized surgical personnel, and antimicrobial prophylaxis), intraoperative issues (operative room environment ventilation, surgical attire and drapes, asepsis and surgical technique), post-postoperative issues (incision care and discharge planning), and wound classification.

The different risk factors of SSI are age, diabetes, smoking, and obesity and pre-operative showering with antiseptic. Patient number two does not has the preoperative showering due to emergency surgery. 
There are no different risk factors found in intra-operative issue and post-operative issue. All patients got the same intervention which was post-operative prevention strategy of SSI. The third patient had the different solution of dressing with chlorhexidine $2 \%$. Based on observation during three days of clinical practice, patient number 1, 2 and 3 did not have the signs and symptoms of SSI. However, patient number 4 admitted to hospital with deep incisional SSI (14 days post-operative SSI diagnosis), and patient number 5 developed SSI (10 days post-operative diagnosis). The risk factors including age, diabetes, smoking and obesity are needed to be observed in post-operative issues. Since the evidence shows that infection might be happen after discharge (Prospero et al., 2006; Reilly et al., 2019).

\subsection{Factors related to SSI}

Age. Four patients were over 40 years old and one patient under 40 years old. The patient over 40 years old had a statistically significantly increased risk of developing SSI compared with those under 40 years old (Neumayer et al., 2007). Based on that finding, four patients had a high risk of SSImand from four patients, two patients developed SSI.

Diabetes. One patient had diabetes and four patients had not. Several studies in cardiac surgery have shown that diabetes is strongly associated with an increased risk of SSI (NICE, 2008). Patient with diabetes in this study did not develop SSI during three days of observation.

Smoking. One patient had a smoking history since a teenager by 10 pieces per day, and four patients had not. Cigarette smoking can inhibit wound healing and blood circulation to the skinmbecause there is an obstruction in micro vascular from platelet aggregation. It can cause the non-functioning of haemoglobin. Smoking also alters the inflammatory response that usually occurs when a surgical wound is made. The alteration of wound healing is defined as SSI if it occurred within 30 days. Smokers had a statistically significantly greater risk of developing SSI compared to non-smokers (Neumayer et al., 2007). In this finding, the patient who had a smoking history did not develop SSI for three days observation.

Obesity. Based on BMI data, one patient was obese, and four patients were not obese. Adipose tissue is poorly vascularized, and the consequent effect on oxygenation of the tissues and functioning of the immune response is thought to increase the risk of SSI. The effect of obesity on the risk of SSI has been investigated in cardiac surgery (NICE, 2008). The obese patient was not diagnosed with SSI, but he had a minimal discharge from the wound.

Malnutrition. The nutrition status of three patients was analyzed by record the lab data, including haemoglobin, red blood cell, albumin, creatinine, BUN, and hematocrit level. The albumin level of four patients was not found, only albumin level of patient number four found 4 (normal). However, by analyzing the abnormal data of haemoglobin, red blood cell, albumin, creatinine, BUN, and hematocrit level, all patients were diagnosed malnutrition. Based on CDC guideline 1999, severe protein calorie malnutrition is crudely associated with nosocomial infections, impaired wound healing dynamics, or death. Patient number four and five had malnutrition and develop SSI.

Perioperative transfusion. It has been reported that perioperative transfusion has an apparent risk factor for the development of postoperative bacterial infections, including SSI (Mangram, 1999). The randomized trials conducted in patients undergoing elective colon resection for cancer, the risk of SSI was at least doubled in patients receiving blood transfusions (Vamvakas, Carven, \& Hibberd, 1996). In this study, all patients had the perioperative transfusion.

Preoperative antiseptic shower. A preoperative antiseptic shower or bath decreases skin microbial colony counts. In a study, there were more than 700 patients who received two pre-operative antiseptic showers, and chlorhexidine was effective to reduced bacterial colony than povidone-iodine (Garibaldi, 1998). However, in this study, four patients had showered with antiseptic soap at night before surgery, and one patient had not due to emergency surgery.

The length of the operation. The length of operation may serve as a marker for the complicated case of a patient undergoing surgery. Some aspect contributes to extend the duration of operation including; surgical technique, prolonged exposure to microorganisms in the operating environment, and lack of efficacy of antimicrobial prophylaxis (Leong, Wilson \& Charlett, 2006). A study conducted in London found operations lasting for a longer time were associated with a higher risk of SSI (Leong, Wilson, \& Charlett, 2006). In addition, in the study of cardiac, there was a 1.5-1.75-fold increased risk of SSI 
associated with linger duration of surgery. All patient with post cardiac surgery had a long duration of surgery which approximately more than 4 hours.

Hair removal. The preoperative preparation in this hospital is needed to be concerned. The hair removal delivered to the patients before referring patient to the $\mathrm{OR}$ using a razor and electric clipper. The nurse removed the hair around sternum using an electric clipper and removed the hair around leg using razor. Pre-operative shaving of the surgical site the night before an operation is associated with a significantly higher SSI risk than the use of depilatory agents no hair removal (Mangram, 1999). Shaving immediately before the operation compared to shaving within 24 hours preoperatively was associated with decreased SSI rates (3.1\% vs $7.1 \%$ ); if shaving performed $>24$ hours before the operation, the SSI rate exceeded $20 \%$ and patients and care giver knowledge about SSI.

\subsection{Surgical site infection finding}

Based on the criteria of SSI by CDC guideline (1999), two patients developed SSI, and three patients did not. Patient number four had the purulent drainage, dehisces of deep incision, fever $\left(>38^{\circ} \mathrm{C}\right)$, localized pain, heat around the wound, finding of S.Aureus in the blood culture, and it was defined as deep incisional SSI. The fifth patient had discharge from the superficial incision and wound dehisces on the leg. This patient had the behaviour to catch his wound and try to open the dressing. It would be to increase the contamination of micro bacteria and lead to SSI.

\section{Conclusion and recommendation}

There are two patients developed SSI in this study. Patient number four had some risk factors, including age, malnutrition, duration of surgery, perioperative transfusion, and hair removal. $\mathrm{He}$ developed the deep incisional SSI. Patient number five had some risk factors included age, malnutrition, duration of surgery, diabetes, COPD, perioperative transfusion, hair removal. He had superficial incisional SSI.

Patient knowledge about SSI is needed to prevent SSI. Based on observation and interview, all patients did not know about SSI and did not aware of SSI. The study conducted in Nepal, examine the knowledge of patient regarding SSI, from 100 patients, $81 \%$ of the patients had no information on SSI. It can be concluded that the patient did not know because they had no information about SSI.

Based on a study conducted in America found that patients thought that education could be provided more frequently including having spent more time talking with the patients regarding SSI may provide more benefit to increase knowledge and awareness to the risk factors of SSI (Anderson et al., 2013). The education intervention about SSI has increased patient knowledge and awareness about SSI prevention. Patients kept his wound clean and did touch their wound anymore.

Regarding patient knowledge and awareness, nurses were less involved in providing information. Hence to enhance patients' involvement in SSI prevention and recognition, the provision of written patient-directed information recommended. The education about SSI is also needed for caregiver to increase their awareness about the sign and symptoms of SSI. A study revealed that the influence of patient participation is becoming an increasingly important concept and advocated as a means to improve patient safety. Since the infection may occur after discharge, the community nursing need to educate patients and motivate them to prevent SSI at home (Tartari et al., 2017).

Preoperative skin preparation of both the patient and the surgical team is essential in the prevention of SSIs. Thus, the surgical team should prepare the skin at the surgical site immediately before incision using an antiseptic preparation, such as povidone-iodine or chlorhexidine that were most suitable. Preoperative bathing/showering with chlorhexidine soap is recommended for preoperative prevention strategy to reduce SSI. The hair removal using an electric clipper is associated with less incidence of SSI compare hair removal using a razor. So, it is recommended to use an electric clipper if hair removal is needed in preoperative skin preparation procedure either in the sternum or leg in the patients post cardiac surgery.

The prevention of surgical site infections is not a result of isolated actions taken by one provider. Instead, it is the objective and desired outcome of an integrated team process. The process of infection control includes including the pre-operative, intra-operative, and post-operative phases. Infection prevention typically provides a variety of services to healthcare organizations. However, the nurse who provides care at the bedside who has the ability to impact infection prevention, resulting in positive 
patient outcomes. The actions of the nurse and other healthcare workers directly impact patient morbidity and mortality. Nurses have a unique opportunity to reduce surgical site infections. Hospital nurse and community nurse need to have adequate knowledge and skill in SSI prevention. Utilizing the skills and knowledge of nursing practice, nurses can facilitate patient recovery while minimizing complications related to infections.

These interventions are integral to the processes of nursing care and are often performed in collaboration with other members of a multidisciplinary healthcare team. Some of the most basic strategies resulting in positive patient outcomes included the practice and promotion of hand hygiene, consistent use of aseptic technique, cleaning and disinfection practice, wound care, use of standard precautions, patient assessment and additional precautions, patient education, use of safety device, removal of unnecessary invasive devices, use of bundle strategies for SSI prevention and fit for duty. Not only the nurse, patients and caregiver should have enough knowledge and awareness to prevent SSI included keep personal hygiene, hand washing technique, maintain nutrition and wound care practice.

\section{References}

Anderson, M., Ottum, A., Zerbel, S., Sethi, A., Gaines, M. E., \& Safdar, N. (2013). A survey to examine patient awareness, knowledge, and perceptions regarding the risks and consequences of surgical site infections. American Journal of Infection Control, 41(12), 1293-1295.

Blackham, A. U., Farrah, J. P., McCoy, T. P., Schmidt, B. S., \& Shen, P. (2013). Prevention of surgical site infections in highrisk patients with laparotomy incisions using negative-pressure therapy. The American Journal of Surgery, 205(6), 647-654.

Edmiston Jr, C. E., Krepel, C. J., Edmiston, S. E., Spencer, M., Lee, C., Brown, K. R., ... \& Seabrook, G. (2014). Empowering the surgical patient: a randomized, prospective analysis of an innovative strategy for improving patient compliance with preadmission showering protocol. Journal of the American College of Surgeons, 219(2), 256-264.

Bridgewater, B., Kinsman, R., \& Walton, P. (2009). Demonstrating quality: the sixth National Adult Cardiac Surgery database report.

Garibaldi, R. A. (1988). Prevention of intraoperative wound contamination with chlorhexidine shower and scrub. Journal of Hospital Infection, 11, 5-9.

Gould, D. (2012). Causes, prevention and management of surgical site infection. Nursing Standard, 26(47), 47-56.

Harrington, P. (2014). Prevention of surgical site infection. Nursing Standard, 28(48), 50-58..

Healthcare-associated Infections (HAIs). (2013). Types of Healthcare-associated Infections. Centers for Disease Control and Prevention. Retrieved from http://www.cdc.gov/HAI/infection Types.html. Accessed February 19, 2015

Hosseinrezaei, H., Rafiei, H., \& Amiri, M. (2012). Incidence and risk factors of sternal wound infection at site of incision after open-heart surgery. J Wound Care, 21(8), 408-411.

Labeau, S. O., Witdouck, S. S., Vandijck, D. M., Claes, B., Rello, J., Vandewoude, K. H., ... \& Blot, S. I. (2010). Nurses' Knowledge of Evidence-Based Guidelines for the Prevention of Surgical Site Infection. Worldviews on Evidence-Based Nursing, 7(1), 16-24.

Leong, G., Wilson, J., \& Charlett, A. (2006). Duration of operation as a risk factor for surgical site infection: comparison of English and US data. Journal of Hospital Infection, 63(3), 255-262.

Mangram, A. J., Horan, T. C., Pearson, M. L., Silver, L. C., Jarvis, W. R., \& Hospital Infection Control Practices Advisory Committee. (1999). Guideline for prevention of surgical site infection, 1999. American Journal of Infection Control, 27(2), 97-134.

National Institute for Health and Clinical Excellence. Surgical site infection. (2008). (Clinical guideline 74.). Retrieved from www.nice.org.uk/CG74

Neumayer, L., Hosokawa, P., Itani, K., El-Tamer, M., Henderson, W. G., \& Khuri, S. F. (2007). Multivariable predictors of postoperative surgical site infection after general and vascular surgery: results from the patient safety in surgery study. Journal of the American College of Surgeons, 204(6), 1178-1187.

Novelia, S., Sia, W. S., \& Songwathana, P. (2017). Nurses' Knowledge and Practice Regarding the Prevention of Cesarean Section Surgical Site Infection in Indonesia. GSTF Journal of Nursing and Health Care (JNHC), 4(2).

Prospero, E., Cavicchi, A., Bacelli, S., Barbadoro, P., Tantucci, L., \& D'errico, M. M. (2006). Surveillance for surgical site infection after hospital discharge: a surgical procedure-specific perspective. Infection Control \& Hospital Epidemiology, 27(12), 1313-1317.

Reilly, J., Noone, A., Clift, A., Cochrane, L., Johnston, L., Rowley, D. I., ... \& Sullivan, F. (2005). A study of telephone screening and direct observation of surgical wound infections after discharge from hospital. The Journal of bone and joint surgery. British volume, 87(7), 997-999. 
Sickder, H. K. (2010). Nurse's knowledge and practice regarding prevention of surgical site infection in bangladesh. doi: 10.5001/omj.2014.68

Tartari, E., Weterings, V., Gastmeier, P. J. R. B., Baño, J. R., Widmer, A., Kluytmans, J., \& Voss, A. (2017). Patient engagement with surgical site infection prevention: an expert panel perspective. Antimicrobial Resistance \& Infection Control, 6(1), 45.

Vamvakas, E. C., Carven, J. H., \& Hibberd, P. L. (1996). Blood transfusion and infection after colorectal cancer surgery. Transfusion, 36(11-12), 1000-1008. 